\title{
UNAMUNO: UNA APORTACIÓN A LA FILOSOFÍA DE LA RELIGIÓN
}

\author{
María José ABELla MAESO \\ Profesora Agregada de Instituto
}

"¿Qué es la historia toda cristiana del hombre, sino un lento desprenderse de la naturaleza para dejar al descubierto el fondo divino...? ¿Qué es más que una continua sobrenaturalización del hombre? $»^{1}$.

La peculiar convivencia "dialéctica" que Unamuno mantuvo con el universo religioso, en particular con el cristiano y su Dios, ha dado pie a muy diversas interpretaciones, a veces incluso contrapuestas, a cerca del tipo de religiosidad que le caracterizó. Y con él, a su obra. Sin embargo, y a pesar de la pluralidad de perspectivas desde las que se ha intentado esclarecer la postura que Unamuno adoptó ante el fenómeno religioso, es curioso comprobar que escaseen la lecturas que relacionan el intempestivo pensamiento unamuniano con la reflexión crítica a cerca del fenómeno religioso, propia de la Filosofía de la Religión. Mi trabajo Unamuno: una aportación a la Filosofía de la Religión no ha tenido otro objeto que venir a llenar este vacío ${ }^{2}$.

En él, he intentado mostrar una faceta de Miguel de Unamuno que, intuida por algunos estudiosos y en continuidad con las ya recreadas o definidas por otros, nos desvela un nuevo aspecto de su siempre compleja personalidad. Al Unamuno agónico, crítico,

\footnotetext{
${ }^{1}$ Diario intimo, VIII, 875. Cito por la edición de Escelicer. Obras Completas, Madrid, 1966-71, IX vols.

${ }^{2}$ Tesis doctoral defendida en la UNED en diciembre de 1994 y dirigida por Manuel Fraijó Nieto.
}

Éndoxa: Series Filosoficas, $n^{2} 7,1996$, UNED, Madrid:

María José Abella Maeso: Unamuno: Una aportación a la filosofía de la Religión.

pp. 179-200. 
suscitador de problemas, hereje, al apolítico, al literato, al profesor, al Unamuno místico, contemplativo y hogareño, se superpone el Unamuno filósofo de la religión, el Unamuno que sin saberlo tiende el puente entre los modos de hacer filosofia del siglo pasado y los surgidos en el presente.

Si indagamos en la biografía de Unamuno, pronto descubrimos que uno de los pilares sobre los que se asienta su relación con el ámbito de la creencia religiosa es el temprano descubrimiento de la fragilidad (desamparo) de lo existente. Experiencia que irá acompañada de un intenso deseo de traspasar los límites que aquella nos impone. Por eso, antes de seguir adelante, es preciso analizar las circunstancias de carácter personal e intelectual que explican y ayudan a comprender el sentimiento de angustia y la desesperación activa, superadora, que determinan su especial vivencia de lo religioso, su visión de la religión como "soteriología existencial", en palabras de Carlos París ${ }^{3}$.

\section{El paisaje y la configuración del alma}

Lo primero que nos sorprende al aproximarnos al hombre Unamuno, es la influencia que el paisaje ejerce sobre él como elemento modelador de la conciencia. El paisaje produce en Unamuno determinadas impresiones que se reflejan en la construcción de su personalidad, al tiempo que cobra un sentido simbólico como manifestación sensible que es de la auténtica realidad. De este modo, cada una de las regiones por donde transcurre șu vida le va a revelar un mensaje que, andando el tiempo, pasará a formar parte de su propia explicación del mundo.

En su Bilbao natal descubrirá que no hay paz sin guerra, que la realidad es, irremediablemente, dialéctica, lucha intestina entre las distintas posibilidades del ser. Pero su ciudad natal, su "bochito", representará sobre todo el retorno a la inocencia

\footnotetext{
3 Tema al que he dedicado unas interesantes páginas en la Filosofia de la Religión, editada por M. Fraijó, Trotta, Madrid, 1994.
} 
perdida, a la fuente de la vida. Porque volver al origen es retornar al lugar donde nacimos, es remontarse al principio esquivando la oscura y misteriosa ultratumba. Volver al origen es recuperar la plenitud primigenia, anterior al enfrentamiento fratricida que inició la historia de la humanidad; es retornar a la inconsciencia de la cuna, en la que todavía no se ha producido la desnaturalización del hombre ${ }^{4}$.

Madrid, frente al acogedor paisaje vasco, supondrá la profunda soledad del existente, el camino de la individuación a la luz de la razón y del ideal moderno. En Madrid, reconocerá la alienación que produce la actividad civilizadora y tomará conciencia del nihilismo contemporáneo, de la vanidad del "progreso" que brota al amparo del incierto oleaje de la historia. Madrid representará el destierro del hombre.

Salamanca, a la que llega en 1891, encierra el secreto del alma castellana, de la intrahistoria de España, aquello que de permanente humano queda en la obra del tiempo. Su profunda identificación con el alma castellana convertirá a Salamanca en la máxima afirmación de lo que hay de más inalienable en el ser español, la tradición eterna española que, por eterna es más bien humana que española ${ }^{5}$.

Con todo, Salamanca será también el lugar donde se produzca el definitivo e irreversible alejamiento de la fe de sus padres. La crisis de 1897 empuja a Unamuno a replantearse el rumbo que hasta entonces había seguido su vida. Escindido entre dos universos contrapuestos, la vieja fe y el racionalismo moderno, la trágica proximidad de la enfermedad de su hijo y de la muerte, a lo que se suma la traumática decepción que la realidad social y política le supone, le obligan a volver sus ojos hacia lo religioso, ámbito por excelencia de los discursos donadores de sentido. A

\footnotetext{
4 Muchas son la obras en las que Unamuno hace referencia a ello: Del sentimiento trágico, Recuerdos de nintez y de mocedad, Paz en la guerra, De mi país,...

${ }_{5}^{5}$ En tomo al casticismo, III 194; Del sentimiento... XVI, 418. A partir de ahora cito por Obras completas, Afrodisio Aguado, Madrid, 1959-64, XVI vols.
} 
partir de este momento, sus frecuentes incursiones en lo religioso responderán más a su personal búsqueda de la plenitud y de la humanidad completa que a un intento de salvar lo poco que en él quedaba de la fe heredada.

Sus continuas disputas con los poderes públicos le llevarán al exilio, Fuerteventura y París, pero fundamentalmente Hendaya le recuerdan el destierro del ser humano. La expulsión de un paraíso que sólo se reconoce como tal cuando se ha perdido y que quizá pueda recuperarse al traspasar el umbral de la muerte. Será, pues, la añoranza del hogar terreno la que le permita vislumbrar el eterno lugar de consuelo, la morada "de antes" y "de después", en que nuestro ajetreado existir cobra su significado. Las antiguas dudas acerca de la resurrección y del sentido de la vida se verán aguzadas por el intenso sentimiento de personal desarraigo. Sentimiento que no disminuirá un ápice cuando, esperanzado, retorne a España a disfrutar del recién estrenado "paisaje" de la República.

Estas experiencias vitales, apenas esbozadas aquí, encontrarán su mejor vehículo de expresión en el constante diálogo con la filosofía europea, fuera del estrecho marco de la "ideocracia" academicista imperante en España. El pensamiento decimonónico, que comprende cuanto hay desde el prisma de una realidad fluyente en la que el juego de las contradicciones explica y provoca el paso de un momento a otro del acontecer universal, encaja a la perfección con lo que el incipiente existencialismo de Unamuno llamará "sentimiento trágico de la vida", la paz que se alimenta de la guerra entre el Todo y la Nada.

Corresponde a Hegel el mérito de haber identificado método y realidad, así como de haber resaltado la función creadora de la nada al situarla en el origen e integrarla en el medio de la tríada dialéctica, asignándole la tarea de actuar como fermento y motor del devenir. Actividad que, trasladada al ámbito biológico bajo la influencia del darwinismo, dará pie a un vitalismo evolucionista que deja la puerta abierta a lo imprevisible, rompe con el determinismo que dominaba los «monismos dialécticos» del XDX (Hegel y 
Marx) y pone en manos de la voluntad, no de la razón, el impulso vital que permite al viviente "serse" (en términos unamunianos), afirmarse y desplegarse en todas direcciones según sus aspiraciones.

Este retorno a lo instintivo y vital, ahogado hasta ahora por categorías lógico-abstractas, junto con la esperanza de que la nada tenga como función potenciar el crecimiento y la expansión, no la muerte, será clave para el desarrollo de la obra unamuniana. Afianzado en la idea de la imperiosa necesidad de devolver al hombre su confianza en sí mismo y apoyándose en las consignas humanizadoras del protestantismo ${ }^{6}$, Unamuno instará a sus contemporáneos a analizar su precaria situación y realizar un proyecto vital propió en el que el hombre despliegue, enriquezca y cree su vivir, no conforme a un plan, sino viviendo.

Lo que supone el abandono de las generalizaciones supratemporales, que se expresan en fórmulas exactas y univocas, en favor de un discurso, ajustado al vivir de cada uno, que se sitúe entre la dialéctica y la dialogía para, así, eludir el reposo de las seguridades definitivas, pero también el desconcierto de un escepticismo insuperable impuesto por la muerte de los absolutos: porque si ésta buscaba redimir al hombre del yugo que su propia admiración por lo infinito le había impuesto, amenazaba, al tiempo, con transformarse en la muerte del impulso creador de la humanidad. La pérdida del sentido transcendente, religioso, metafisico, que Unamuno constata se produce en Europa, podrá enseñarnos cómo vivir, mas ¿no nos incapacitará para dar sentido a ese nuestro vivir?

Renunciar a los absolutos no ha de suponer, piensa nuestro autor, la supresión de todo ideal humano, de la aspiración a la

${ }^{6}$ Según Dewey la influencia del protestantismo se dejó sentir en toda Europa al desplazar la perspectiva religiosa de las instituciones al hombre, defendiendo el valor intrínseco de cada alma (La reconstrucción de la filosofía, Planeta, Barcelona, 1993). Aranguren y Orringer, entre otros, han dedicado importantes páginas a establecer la base protestante de la reflexión unamuniana. Aranguren, J. L., Catolicismo y protestantismo como formas de existencia, Alianza, Madrid, 1980; Orringer, N. R., Unamuno y los protestantes liberales, Gredos, Madrid, 1985. 
plenitud. Se trata, como vemos, de reintegrar al hombre en la infinitud, como pretendía Hegel; pero, a diferencia de él, sin prescindir del diálogo con el hombre. Se trata de acabar definitivamente con el carácter impersonal que ha caracterizado la reflexión filosófica occidental desde Platón hasta Marx, para dotar al quehacer humano de finalidad, de verdadero "prot-agonismo". Aspiración que logra su objetivo cuando comprende al hombre como sujeto que propone los fines y que se presenta a sí mismo como un fin más integrante de la totalidad de lo existente.

\section{La búsqueda del sentido}

Las anteriores consideraciones me convencieron de que los tres grandes temas unamunianos (personalidad, inmortalidad, Dios), en torno a los cuales gira toda otra preocupación, se reducen en definitiva al interés por el sentido de la existencia individual, de la sociedad en que ésta se desarrolla e, incluso, del Universo, en cuanto totalidad en que se enmarca la realidad del existente. ¿Para qué tanto esfuerzo si al final nada queda, nada se logra? Ateniéndose a ello es posible reunir la problemática unamuniana en la trilogia: "ansia de ser, de ser siempre, de serlo todo"7.

El "ansia de ser", como impulso básico de lo existente, se expresa en el hombre a través del espíritu personalizador, cuya tendencia creadora libera al ser humano de las ataduras materiales e ideológicas (propias de los "intelectuales") que le limitan e individualizan. Dicha liberación se realiza cuando aprendemos a ver la realidad no como "individuos" ajenos a élla, independientes, sino como "personas" comprometidas con lo existente ("espirituales"). La personalidad, frente a la "individualidad", habla de nuestra infinitud, de la posibilidad de alcanzar la conciencia de lo que de "divino" (Hegel) hay en el hombre, de nuestro anhelo de ser nosotros mismos (Kant) y serlo siempre.

${ }^{7}$ Rivera de Ventosa, E., Unamuno y Dios, Encuentro, Madrid, 1.985, 29. 
Tras desestimar las distintas soluciones que se han dado al problema de la inmortalidad por entender que, de un modo $u$ otro, todas atentan contra el fundamental deseo de conservar la integridad dinámica de la persona, Unamuno propone una particular visión de la transcendencia en la que queda recogida la esencial contradicción de todo lo vital. Sólo si se mantiene la lucha esencial, el poder creador inherente a la posible frustración de la esperanza (Bloch), se mantendrá la vida. De manera que el temor al fracaso, el eterno querer serlo todo para no caer en la nada, sin llegar nunca al Todo, se convierte en el verdadero "principio de sentido", en tanto nos empuja a vivir de manera que no merezcamos morir, que la muerte sea una injusticia.

Ahora bien, "el anhelo de la inmortalidad del alma, de la pervivencia, en una u otra forma, de nuestra conciencia personal e individual, es tan de la esencia de la religión como el anhelo de que haya Dios. No se da el uno sin el otro, y es porque en el fondo los dos son una sola y la misma cosa». Porque Dios es dador de inmortalidad, sustentador de sentido. Desde esta concepción de la supervivencia no le queda más remedio que meditar sobre lo religioso, pero meditar "existencialmente".

Separado de su vieja fe y decepcionado de la razón, Unamuno se anticipará al positivismo lógico al reconocer que la razón, más que desentenderse, desconoce el deseo de no sucumbir a la nada, mientras la fe es incapaz de justificar su promesa de salvación. De la confrontación entre ambos mundos surge la fe agónica, la desesperación esperanzada que le lleva a concebir a Dios, el Todo que anhelamos, como un Dios sufriente, un Dios por hacer, compendio de las almas todas, en el que se armonizan las personalidades. Un Dios creado por la síntesis de las voces que intervienen en el diálogo universal y que constituye, al tiempo, la plenitud de la conciencia, de la humanidad, ansiada por todos, garantía de la inmortalidad.

\footnotetext{
${ }^{8}$ Del sentimiento..., XVI, 347
} 
Es el deseo de eternizarnos el que nos lleva, según Unamuno, a "crear" a Dios"

Necesitamos a Dios para salvar al universo de la Nada, para asegurarnos una conciencia eterna. Así, el concepto de divinidad surge del sentimiento de ella, del sentimiento de personalidad vertido a lo de fuera. Dios asegura la continuidad y el sentido vital. Dios es el hombre proyectado al infinito y eternizado en El. El Dios de que habla Unamuno no es el Espíritu puro o el Ser supremo de los filósofos, sino un Dios de la esperanza y del sentimiento, el Universo mismo personalizado, la Conciencia plena.

El Dios de Unamuno nace de una aspiración, y puesto que el deseo no determina la existencia de lo deseado, su Dios cordial no se presenta como una realidad objetiva ya dada, sino como posibilidad, como tendencia universal a la plena realización de lo espiritual, que puede verse truncada. El gran Autor se convierte entonces en ficción, al tiempo que sueña a sus personajes (criaturas), es soñado por ellos, que recrean y descubren su personalidad.

A la luz de lo anterior podemos destacar como nota esencial de la obra unamuniana el empeño por encontrar, desde el "subjetivismo personalista", un "principio de sentido" que, basado en el juego de oposiciones, recupere el "impulso creador", transcendente, propio de la humanidad y conservado celosamente en sus manifestaciones religiosas. Dicho empeño es precisamente lo que me ha permitido proponer esta nueva lectura de su obra.

\section{Unamuno y la Filosofía de la Religión}

Lo cierto es que Unamuno nunca llegó a escribir la Filosofía de la Religión que anunciaba en carta a Múgica, ni a ocupar la cátedra de Filosofía de la Religión que Ortega quería crear para él en Madrid, pero no menos lo es que su obra guarda, en conjunto,

${ }^{9}$ La agonía del cristianismo, XVI, 471 
estrecha relación con lo que Fraijó denomina «filosofías de la religión realizadas».

La postura que Don Miguel adopta ante el hecho religioso, me atrevo a decir, está más próxima a la del filósofo que a la del creyente, por cuanto, como declara en su Diario íntimo, no se acerca al fenómeno religioso con ánimo de adscribirse a una determinada manifestación histórica. Más bien, se sitúa en los márgenes de la religiosidad para, desde allí y por simpatía, analizar comprensivamente la esencia y función de un sentimiento, inherente a la humanidad, que se ha concretado en las distintas confesiones religiosas. Perspectiva que ya adopta en su primera y reveladora, obra Nuevo mundo, inédita hasta hace unos meses.

Tanto es así, que para él, como para Hegel, lo religioso esconde, tras un ropaje simbólico, un núcleo racional que expresa la verdad de lo real: el anhelo de autocomprensión del Espíritu, consecuencia del temor o rechazo al vacío que se manifiesta en el deseo de que la eternidad sea lo que nos está reservado.

Ahora bien, mientras en el alemán lo racional se convierte en vehículo de presentación de las cosas ante la conciencia, en Unamuno es lugar de revelación de las mismas, porque la verdad vital, apunta García Bacca ${ }^{10}$, no puede demostrarse sino que debe, de acuerdo con su naturaleza dinámica, mostrarse.

Motivo por el cual, Unamuno intentará salvaguardar el lenguaje metafórico (poiético) en que se expresa la verdad existencial (religiosa o metafísica) de los ataques de la razón analítica, no apta para indicar las transformaciones del pensamiento en su andadura hacia la conciencia. De ahí que para él, hacer filosofía no seà hacer ciencia, sino religión o poesía, en tanto ambas representan el intento humano de acrecentar la conciencia.

Poesía, religión y metafisica brotan de nuestra forma de enfrentarnos a la vida y a su contrapartida, la muerte. No son, como la ciencia, el resultado del deseo de ampliar nuestro conoci-

${ }^{10}$ Garcia Bacca, J. D., Unamuno o la conciencia agónica, recogido en Nueve grandes filósofos contemporáneos y sus temas, Anthropos, Barcelona, 1.990, 86 y 87 
miento sobre la realidad. Es más, cada una de éllas guarda estrecha relación de necesidad con respecto a las demás.

La obra poética es la expresión de los denodados esfuerzos del hombre por desvelar el enigma de la vida, el misterio de la Esfinge. La auténtica creación poética, no los sucedáneos que se ahogan en falsas aspiraciones estéticas, es un laboratorio donde se experimentan las posibilidades de ese ir haciéndose, contra la nada, que es la existencia del hombre.

Por su parte, la filosofía, aun cuando construya con la razón, lo hace desde la voluntad de ser, desde el sentimiento, porque no es posible referirse a la vida si de antemano se prescinde de aquello que nos mantiene vivos. Es la actitud ante la vida la que genera los innumerables sistemas metafísicos, de ahi que estos no representen más que el intento del filósofo, del hombre, de explicarse a sí mismo la vida. Los grandes sistemas metafisicos son grandes poemas que intentan expresar la verdad.

Otro tanto sucede, según Unamuno, con la religión. El hecho religioso expresa la experiencia de finitud y contingencia del ser humano que se siente desterrado en un mundo hostil al que ha de enfrentarse. La religión, una vez depurada de los elementos alienantes y dogmáticos (Feuerbach), se convierte en un vehículo tan apropiado de la verdad como pueda serlo la filosofía. Y aún irá más lejos al afirmar que la "historia de la filosofía es, en rigor, una historia de la religión" ".

Desde esta perspectiva es posible defender que su interés por lo religioso, como en cierto modo sostienen París, Laín o Aranguren, pero sobre todo Marías, responde más a una "secularización imperfecta", a una pérdida de la fe que no logra alcanzar su grado último, que a un encubierto ateísmo. Hasta el punto de que el ropaje cristiano con que Unamuno reviste su exposición depende de su necesidad de mostrar la verdad religiosa, transcendente, agotando las posibilidades de un lenguaje familiar, y no de una

${ }^{11}$ Del sentimiento..., XVI, 242 
heterodoxa adhesión al dogma cristiano o de un caprichoso agnosticismo teológico, como señala Serrano Poncela con acierto ${ }^{12}$.

Unamuno no se centra en la posibilidad de un Dios creador y señor del mundo. Para él, Dios no es más que cifra de la "sobrenaturalización" que da sentido al acontecer universal. Baste recordar el pasaje en que, en Del sentimiento trágico, expresa el sueño de que el Universo haya comenzado con un todo de materia y un cero de espíritu, para concluir en un todo de espíritu y un cero de materia.

La religión expresa la tensión entre el deseo tanático de retornar a la nada primigenia (des-nacer) y la aspiración erótica de serlo todo (eternizarse). Tensión que se resuelve en una desesperación esperanzada, la agonía, cuya traducción ontológica será el poder superador inherente a la posible frustración de lo "aún-noacontecido" (Bloch).

Concepción que le llevó a querer dar nueva vida a la religión apelando a la riqueza humana y al contenido existencial que en aquélla se esconden. Un propósito que, estimo, puede enmarcarse dentro del esfuerzo crítico, flexible, riguroso y no confesional por explicar y comprender el hecho religioso que $M$. Fraijó considera característico de la Filosofia de la Religión ${ }^{13}$. A este respecto, he señalado como rasgos relevantes de su filosofía de la religión los siguientes:

1.- La primacía que concede a lo antropológico sobre lo teológico. Primacía que se traduce en su explicación del origen de las religiones y del sentimiento religioso apelando a la peculiar vivencia que el hombre tiene de su propia limitación.

En Unamuno, el interés por descubrir en el fenómeno religioso lo especificamente humano desplaza la tradicional preocupación de la filosofía por la naturaleza y justificación de Dios (teologia

\footnotetext{
157.

12 Serrano Poncela, D., El pensamiento de Unamuno, F.C.E., México, 1978, 156 y

${ }^{13}$ Fraijo, M., «Filosofía de la religión: una azarosa búsqueda de identidad», recogido en Fraijo, M. (Ed.), Filosofía de la religión, Trotta, Madrid, 1994
} 
natural y teodicea). De ahí que, con los filósofos de la sospecha, ensaye un nuevo discurso (el de la razón cordial) del que queden excluidos los instrumentos propios de la razón "mecánica", decantándose por la atención a todas las capacidades humanas (volitiva, imaginativa, sentimental, intelectual, etc.) que integran la experiencia religiosa.

Pretensión, esta última, que le llevará a acercarse al fenómeno religioso desde el compromiso con el creyente y a intentar elaborar. una metodología adecuada al estudio de la actividad creadora del hombre que integre lo irracional humano en una nueva forma de razón, la cardiaca, gracias a la cual se podrá acceder al mundo de la convicción religiosa sin desvirtuarlo.

2.- El segundo factor destacable de su Filosofía de la Religión sería la consideración de que la espiritualidad humana ni puede explicarse con la sola intervención de la razón, ni restringirse a la mera creencia. Su riqueza y variedad, su ambigüedad y equivocidad precisan del lenguaje polivalente de los símbolos para expresar las más profundas aspiraciones humanas, la realidad nunca objetivable de la espiritualidad que se hace cifra, por utilizar la terminología de Jaspers, permitiendo el libre juego de la imaginación, el reconocimiento de una verdad substancial que no puede descubrirse en el cerrado concepto, fruto del pensamiento estático, sino en el evocador símbolo que refleja la apertura creadora del alma humana.

Por eso, para Unamuno, la reflexión sobre el hecho religioso debe tener en cuenta que la religión es el lugar donde se muestra y concreta lo real-posible en cuanto aspiración a la realidad substancial expresada en el lenguaje simbólico. Y dada la naturaleza polivalente del símbolo, Unamuno considera imprescindible acercarse al hecho religioso desde la simpatía con el creyente, buscando en él una experiencia de donación de sentido que responde a la necesidad de tener una visión organizada e inteligible del mundo.

Siendo así y en tanto resultante de la compleja actividad humana, la religión, como la ciencia, representa el intento de 
encontrar respuesta a los múltiples desafios que la existencia plantea. Por lo que participa, en pie de igualdad con otras formas de conocimiento, de la racionalidad propia de toda manifestación humana, de la innovación y gratificación característica de la creatividad del hombre.

3.- Consecuencia de lo anterior será su atención a la pluralidad de las manifestaciones religiosas, ya que, como subraya Caffarena ${ }^{14}$, toda narración religiosa representa para Unamuno el deseo de que lo real sea inteligible y benéfico. Postura claramente afin a la que debe adoptar la Filosofía de la Religión y que en la filosofía de la religión de nuestro autor se concreta en cinco aspectos básicos:

- Su idea de que la historia de las religiones es la historia de la lucha humana por la conquista de la conciencia personal. Una lucha que es reflejo de la esperanza depositada en la renovación de la vida como superación de las limitaciones que la materia impone a la voluntad.

- La concepción de que la religión es lugar de encuentro del hombre consigo mismo (Feuerbach), por lo que no hay esencia de la religión, sino que esta se hace con el hombre.

- No cabe, entonces, hablar de una religión verdadera de la que las demás sean sólo manifestaciones primitivas o degradadas (Rahner), sino que todas son válidas si satisfacen el esencial anhelo de encontrarle sentido al Universo.

- En este sentido, la reflexión sobre lo religioso habrá de respetar (en contra de lo que opinen Feuerbach, los filósofos de la sospecha o sus herederos) el ideal de transcendencia presente en toda manifestación religiosa.

Esta concentración en el aspecto antropológico de la religión ha provocado la reacción de algunos autores que reprochan a Unamuno haber olvidado la imprescindible presencia de lo numinoso como segunda realidad implicada en la creencia. Así, al hablar de

${ }^{14}$ Caffarena, J.G. (Ed.), Religión, Trotta, Madrid, 1993, 16 
la oración en Unamuno, Marrero o Rivera de Ventosa ${ }^{15}$ interpretan que aquél renuncia a la esencial actitud de escucha, propia de quien en un acto de fe se pone a disposición de la voluntad divina, convirtiendo la plegaria en mero canal de desahogo para el alma angustiada. Sin embargo, los textos unamunianos indican una clara conciencia de la doble dirección que se establece en la plegaria, pues si bien ésta se constituye como esfuerzo humano por acceder a Dios, también asume y expresa el descenso de la divinidad al hombre (Barth). Otro tanto ocurre con su visión de la comunidad y el culto, los cuales representan tanto la tendencia de la humanidad a vivir en unanimidad de sentido, la tradición que conforma la herencia espiritual de la humanidad, como la revelación de lo numinoso en un Yo común que nos abre las puertas a la transcendencia.

Por todo ello, estimo que las críticas sobre la lectura que Unamuno propone, en vez de ir enfocadas a su comprensión del fenómeno religioso, deberían centrarse en aquellos factores de su explicación que no parecen concordar entre sí. En efecto:

- Afirmar que Dios es el compendio de todas las almas, al tiempo que se le concibe como una realidad a cuya voluntad hay que ceñirse, supone: o bien que las voluntades de todos se resuelven en una, algo que Unamuno no admite por suponer la disolución personal; o bien, que tendremos que aprender a elegir entre el coro de voces aquella que nos está reservada por designio divino, lo que no parece fácil si consideramos que la armonización de voluntades no supone supresión de lo distinto y opuesto.

- Por otra parte, su concepción de la comunidad y el cultó como manifestaciones vivas de la búsqueda de una verdad espiritual común encaja mal con su ardiente defensa de la evolución transcendente superadora de las diferencias, porque por experiencia sabemos que la evolución suele producirse cuando una idea innovadora choca con la vieja tradición, cuando la verdad de

15 Rivera de Ventosa, E., op. cit., 226; Marrero, V., El Cristo de Unamuno, Rialp, Madrid, 1960, 96 
quienes se rebelan contra lo establecido se enfrenta al afán de la comunidad por entorpecer su expansión y sofocarla.

En realidad, ambas críticas hunden sus raíces en la tendencia relativizadora de la doctrina unamuniana: si todas las religiones son válidas en tanto hacen vivir a sus creyentes, todas surgen de las mismas necesidades y, por ello mismo, todas tienen razón y todas están equivocadas. ¿Por qué seguir, entonces, una determinada confesión si cualquiera es en última instancia tan válida como las demás? Unamuno responde que debemos atender a aquella que más simpatice con nuestra particular vivencia de la realidad, pero en ese caso ¿no sería mejor prescindir de la comunidad de los fieles para seguir el camino de nuestra propia verdad, tomando del culto sólo aquello que pueda enriquecernos como personas? $Y$ en esta línea, ¿se podría afirmar que la verdad alcanzada por un sólo individuo conforma un relato religioso de la realidad? ¿No es acaso esencial en la religión el concepto de reunión de fieles en una sola verdad?

Algo de luz arroja Caffarena cuando recuerda al cristiano que el creyente sólo participa de la «Verdad Absoluta» desde la finitud y que, por tanto, debe aceptar que los que alcanzan alguna verdad, aunque sea por otros caminos (tolerancia), comparten también aquélla $^{16}$. El problema subsiste, no obstante. Porque, a pesar de que esta explicación pretende evitar el relativismo que afecta a la creencia en la "Realidad a la que toda búsqueda humana querría referirse, la Verdad Absoluta" (en un sentido ontológico), ello no impide la dispersión e individualización de las vías de acceso a dicha Verdad y la consecuente disolución de la comunidad religiosa tradicional.

Pese a las críticas, podemos afirmar que el marco en que se desenvuelve la obra unamuniana, centrada en la reflexión sobre la esencia y función de lo religioso, es el de la Filosofía de la Religión, por cuanto ésta concibe lo religioso como reflejo del

${ }^{16}$ Caffarena, J.G., "Hay una aportación cristiana para un nuevo humanismo", recogido en A.A.V.V., Etica día tras día, Trotta, Madrid, 1991, 106 
esfuerzo humano por dotar de sentido al acontecer cósmico, por responder a las cuestiones y preocupaciones que el mundo $y$, en especial, los otros suscitan.

Reflexiones que avalan mi propuesta de interpretar la obra unamuniana como una aportación española a la Filosofia de la Religión. En primer lugar porque Unamuno establece definitivamente la experiencia concreta de la voluntad y el sentimiento como formas de conocimiento propias de la realidad humana y de sus creaciones. $Y$ no olvidemos que esa misma pretensión han tenido autores como Kant o Schleiermacher primero y Kolakowski después.

Desde la perspectiva del sujeto de conocimiento, el mundo material, el conceptual y el espiritual tienen su fundamento en lo irracional, en la selección arbitraria de los factores que nos son imprescindibles para continuar viviendo. La diferencia entre ellos estriba en que para cada uno hay un contexto de descubrimiento y de justificación que no deben aplicarse en un nivel distinto al que les es propio (como de hecho han intentado hacer los filósofos analíticos con el lenguaje religioso).

Unamuno abogará por el carácter cognoscitivo de las proposiciones religiosas, anticipándose al reconocimiento de los postulados de la afirmación, la coherencia y la verificación, propuestos por Scholz (1.936) en su polémica con Barth, como postulados propios del ámbito religioso.

La segunda aportación importante de Unamuno a la Filosofía de la Religión será su insistencia en el valor renovador de la ausencia de seguridades en la religión y su concepción de la fe, no como un don, sino como un deseo desesperado de confiar, de mantener vivo el ideal de transcendencia, la añoranza del establecimiento de la bondad y justicia cósmicas. Terminando, asi, con la aspiración a adhesiones incondicionales y con los extremismos de toda índole, que entorpecen la aproximación a interpretaciones más reveladoras y profundas del enigma de la vida.

En él, la religión se convierte en acicate para la consecución del ideal, de que lo terreno no sea la última palabra (como quería 
Horkheimer), y se entiende como vía de doble dirección que va del hombre a Dios y de Dios al hombre. La religión es al tiempo camino de esperanza y de revelación. Con lo que se abre un nuevo sendero para la teologia, que encuentra su expresión en el Dios sufriente que representa lo «aùn-no", y se retorna a los origenes de la religión como promesa, como anticipación, nunca certeza, de un final problemático que moviliza las reservas espirituales del hombre y lo empuja a la disidencia y la rebelión, en palabras de Muguerza o, desde otra perspectiva, de Fraijó.

Es por esto por lo que Unamuno renuncia a toda pretensión, tácita o no, de erigir una confesión determinada en paradigma de la religiosidad, al modo en que Rahner eleva al cristianismo a la categoría de modelo absoluto en detrimento de todas las demás religiones.

No debemos concluir sin hacer referencia a aquellos aspectos que, en su acercamiento al fenómeno religioso, creo ha descuidado Unamuno. La religiosidad "escéptica", cautelosa, la religiosidad como desesperación esperanzada, no cabe duda de que puede potenciar la lucha por la espiritualidad y de que tiene el mérito de depurar lo religioso de lecturas interesadas o unilaterales, pero es innegable que, en cierto modo, distorsiona el contenido esencial de la religión. No sólo porque en muchas de sus manifestaciones no encontramos rastro alguno de duda, sino porque ni siquiera en aquellas confesiones en que tienen cabida la tentación y la prueba hallamos una incertidumbre tan radical como la que en el fondo de su alma experimentan quienes no reconocen ningún sentido al mundo y sienten que éste está abocado a su disolución en la nada.

En su estudio del fenómeno religioso, echamos de menos un análisis más amplio y profundo de otras confesiones que no fueran la que por proximidad cultural mejor conocía, lo que probablemente habria evitado el que se lanzase a una interpretación tan generalizada sobre la experiencia religiosa y, quizá, le habria obligado a desarrollar el esbozo que en Del sentimiento trágico de la vida realiza sobre el origen y evolución de las religiones. 
El estudio comparado de las religiones nos enseña que, a pesar de sus semejanzas y de la evidente relación que unas manifestaciones y otras guardan entre sí, se dan entre éllas diferencias importantes que Unamuno no parece haber tenido en cuenta. Por ejemplo, la idea de que el esfuerzo humano por dotar de sentido a la realidad va necesariamente unido a la aspiración a la inmortalidad no es constitutiva de todas las religiones.

Tampoco la función de lo religioso es la misma en todos los grupos humanos, incluso dentro de una misma confesión se dan variaciones históricas. En unos casos, su función ha sido la de señalar al hombre el camino de la transcendencia mientras en otros se ha limitado a mantener la convivencia armónica, no transformadora, del hombre con su mundo; en ocasiones, ha servido para determinar y preservar las señas de identidad de un pueblo o para potenciar la cohesión social, etc.

No obstante, tomada en su conjunto, la obra unamuniana tiene el mérito de haber enseñado el camino a la Filosofía de la Religión para evitar los dos grandes males que la amenazan. Me refiero a la racionalización de lo religioso o a su reducción al terreno de lo sentimental, al olvido.

Resaltó también la importancia de recuperar la dimensión espiritual perdida en Occidente, mediante la apertura de la razón a nuevas formas que integran lo irracional humano (volitivo) y el compromiso con la realidad de la vivencia religiosa.

Aun cuando, como señala C. París ${ }^{17}$, hubiera sido conveniente que delimitara mejor su concepto de "razón cordial", la razón desiderativa que se alimenta del diálogo entre la razón analítica y la voluntad, lo cierto es que logró potenciar la exploración de un mundo concebido como una realidad abierta, en continuo proceso de superación.

17 Paris, C., Unamuno. Estructura de su mundo intelectual, Anthropos, Barcelona, 1989, 241 


\section{Conclusiones:}

Profundamente receptivo ante cualquier propuesta liberadora que tendiera a ensanchar y acrecentar los límites de la conciencia humana, Unamuno no pudo por menos que sumergirse en la heterogeneidad cultural reinante a finales del siglo XIX para participar, sin reservas, del nacimiento de una filosofía alternativa que permitiera la emancipación de las ataduras impuestas por los viejos relatos legitimadores, por las mitologías esclavizantes que imponían sus valores y sus códigos ideológicos matando cualquier atisbo de originalidad o diferenciación.

Frente a la monotonía discursiva de la modernidad y con la mirada puesta en la transformación del texto de la historia, nuestro castellanísimo vasco intentará entablar un diálogo con el auditorio social, animándole a intervenir en la autoría de una nueva narrativa social y humana en la que cupiesen todas y cada una de las voces que hasta entonces habían sido sofocadas por la autoridad del grupo cultural dominante (no necesariamente el grupo político o económico dominante).

Sus gritos, sus diatribas, su aparente narcisismo, sus "herejias" no son más que los medios de los que se sirve para satisfacer la imperiosa necesidad de afianzar el derecho de cada hombre a decidir sobre su propia vida, a colaborar en la creación de una conciencia colectiva más rica en matices y posibilidades, poniendo en entredicho las hegemonías exclusivistas, la moral de clase de los antiguos textos cerrados que frenaban la historia ${ }^{18}$. Sus lecturas críticas del pasado intentan delatar las invenciones retóricas de la "ideocracia" y sus concreciones históricas (tradición, Estado, Iglesia...); sus personajes representan el esfuerzo por problematizar el sujeto y su aislamiento existencial; su énfasis en las relaciones comunicativas como formas de co-creación y formación del yo subrayan la importancia del ejercicio de la duda y la contraposición epistemológica y ontológica; los vacíos y los silencios, los trazos inconclusos de su obra manifiestan su concepción abierta y

${ }^{18}$ El ideal histórico, IX, 991; Cómo se hace una novela, X, 893; Conversación I, IV, 550 
profética de un nuevo quehacer filosófico que revela la inagotable potencialidad del presente $\mathrm{e}^{19}$.

En Unamuno todavía late el viejo ideal de fundamentación, sólo que privado del cariz absolutista que le dieran autores como Leibniz o Hegel. Su Dios es un Dios a medio hacer. Armonía universal futura, aún posibilidad, finalidad espiritual del Universo que supone tensión de lo finito a transcender sus límites, fundamento de todo esfuerzo de la vida concreta por hacerse un alma, resultado del trabajo común de todo lo existente por liberarse de sus ataduras materiales; en definitiva, lugar de plenitud aún no realizada, pero factible, en que concluye lo disperso, lo plural, lo descentralizado; lugar, también, donde lo indeterminado encontrará su determinación como conciencia personal comprensiva de lo "otro-propio" e integrado en lo "ajeno-semejante" -no idéntico-.

Su causa es una causa universal al modo de los grandes relatos legitimadores: los pequeños sueños, lo fragmentario y puntual, lo instantáneo y episódico, lo cotidiano salta a primer plano, pero siempre convertido en motivo de reflexión, en pretexto para poner en marcha el juego integrador de oposiciones (razón cordial), aquel que toma en cuenta toda postura posible con miras a comprender y reconciliarlas todas.

Su escepticismo, aunque no metódico, busca la verdad, una verdad práctica, no ideal, que nos haga avanzar por el camino del espíritu. No es un destino, ni huye de la elucubración. Está dispuesto a la interpelación, pero no se deja impresionar por las luces de neón, las frases elocuentes, la publicidad, la falsa tolerancia, la superficialidad; no se deja arrastrar hacia la uniformación de pautas y conductas, la vana retórica de políticos, sociólogos, filósofos y teólogos, sino que defiende el valor de la tradición, de la verdadera, la espiritual, en la que caben las peculiaridades de cada pueblo, de cada casta histórica, esencia de la humanidad.

Unamuno supo desechar cuanto de negativo había en el pensamiento moderno, pero evitando caer en el abismo nihilista que se

${ }^{19}$ Cómo se hace une novela, X, 893; La agonía del cristianismo, XVI, 552 
abría ante la postmodernidad. En ello radica su importancia, en haber dado nuevo sentido a los ideales que la modernidad no supo o no pudo realizar, en «haber sabido oponer al hombre ideal y abstracto, y al superhombre, una moral de batalla que supone actuar desde el fondo mismo de la duda, aun contra sí mismo ${ }^{20}$, prescindiendo de las convenciones institucionalizadas, de la lógica simplista de la falsa universalización. Unamuno nos devuelve a la interioridad creativa de donde surge todo impulso verdaderamente renovador, recuperar para la muerta filosofia el espíritu que las certezas de la modernidad y los lugares comunes de la postmodernidad habian enterrado.

La muerte de Dios, la muerte del Autor, la desaparición de toda voz monódica o autoritaria no supone para él la renuncia a los universos de sentido, o mejor, a la esperanza, conservada en lo religioso, de que a la postre el mundo tenga significado, merezca la pena; de que el vacío, la nada o el absurdo no se adueñen del espíritu y lo venzan.

Su grandeza consiste en haber adelantado una solución, una salida para el ocaso por el que habría de atravesar nuestro siglo XX. Y lo hizo - como nos recuerda Savater ${ }^{21}$ - restaurando el impetu religioso, el impulso agónico que aspira a superar la fragmentariedad y la finitud a través de una ética práctica que supone la invasión de los otros y, no lo olvidemos, la consecuente entrega a ellos.

Porque, «en el individualista Unamuno, en el paroxismo agónico de la conciencia que nos transmite de un modo tan impresionante, ... se nos invita a seguir reflexionando sobre los grandes problemas de la muerte, la soledad, el lugar del hombre en el $\operatorname{cosmos}^{22}$; a continuar preguntándonos por qué hemos de

20 ZAVALA, I. M., Unamuno y el pensamiento dialogico, Anthropos, Barcelona, $1991,66$.

${ }^{21}$ Savater, F., «Prólogo a Del sentimiento trágico», Alianza, Madrid, 1986, 16

22 Paris, C., Tiempo y modernidad, Cuadernos Hispanoamericanos, Madrid, Feb.Marzo (1987), 440-41, 173 
vivir hoy y no ayer o mañana o siempre; por qué no nos es posible escapar a una lógica impuesta por leyes que nos son ajenas; o por qué nos hicieron prisioneros del espacio, del espacio concreto de nuestro existir ${ }^{23}$; en definitiva, por qué nuestro ser es éste y no otro; por qué no podemos ser todo a la vez y eternamente.

Unamuno nos incita a perpetuar la búsqueda del para qué de la existencia con el fin de que dicha búsqueda fructifique en espiritu. Su obra se construye como un titánico esfuerzo revolucionario que hunde sus raices en la religiosidad para devolver a la humanidad el más profundo sentido de la existencia guiado por la necesidad de despertarla al sueño de la vida.

Unamuno quiso dar nueva vida a una religiosidad moribunda que, por ser depositaria de la riqueza humana y existencial de Occidente, podía devolver la esperanza a los vencidos del pasado, del presente y del futuro. Por eso, revisó todas y cada una de las verdades convertidas en dogma, reinterpretándolas.

$Y$ es el resultado de su reinterpretación lo que convierte a la obra unamuniana en una filosofía de la religión realizada. En una filosofía de la religión que, centrada en el hombre, se abre a las distintas manifestaciones del anhelo humano de encontrarle sentido a la existencia, rechazando cualquier intento de obstaculizar el progreso espiritual que lleva a la humanización plena.

${ }^{23}$ Conversación II, IV, 559 